\title{
OPEN Metabolic syndrome markers and risk of hyperglycemia in pregnancy: a cross-sectional cohort study
}

\author{
Joice M. Vernini ${ }^{1}$, Bianca F. Nicolosi ${ }^{1}$, Mariana A. Arantes ${ }^{1}$, Roberto A. Costa ${ }^{2}$, \\ Claudia G. Magalhães ${ }^{2}$, José E. Corrente ${ }^{3}$, Silvana A. M. Lima ${ }^{4}$, Marilza V. Rudge ${ }^{1,2}$ \& \\ Iracema M. Calderon ${ }^{1,2 \bowtie}$
}

The aim was to assess the role of Metabolic Syndrome (MetS) diagnostic markers, recommended by three different guidelines, in the prediction of hyperglycemia in pregnancy. This cross-sectional cohort study included 506 non-diabetic women, with a singleton pregnancy, who underwent a diagnostic test for hyperglycemia at 24-28 weeks. Clinical, anthropometric, and laboratory data were obtained. The relationship between MetS markers and the risk of hyperglycemia was evaluated by backward stepwise logistic regression analysis $(\mathrm{OR}, 95 \% \mathrm{Cl})$. The limit of statistical significance was $95 \%(p<0.05)$. Triglycerides (TG) $\geq 150 \mathrm{mg} / \mathrm{dL}$, blood pressure (BP) $\geq 130 / 85 \mathrm{mmHg}$, fasting glucose $(\mathrm{FG}) \geq 100 \mathrm{mg} / \mathrm{dL}$, and waist circumference $(\mathrm{WC})>88 \mathrm{~cm}$ were identified as independent risk factors for hyperglycemia in pregnancy. These results might help the selective screening of hyperglycemia in pregnancy.

Metabolic syndrome (MetS) is a clustering of clinical and laboratory abnormalities that include central obesity, insulin resistance, hypertension, hyperglycemia and dyslipidemia (elevated triglycerides and reduced HDLcholesterol levels). MetS represents a high socioeconomic burden as it significantly increases the risk of cardiovascular disease (CVD), and metabolic disorders such as type 2 diabetes (DM2) ${ }^{1-3}$. In 2008, Bartha et al. ${ }^{4}$ proposed cutoff values for the diagnosis of MetS during pregnancy.

Gestational diabetes mellitus (GDM) is defined as any degree of glucose intolerance diagnosed in the second and third trimesters of pregnancy with different degrees of maternal hyperglycemia ${ }^{5}$. GDM is the most common metabolic disorder of pregnancy, and it shows facets of MetS including obesity, insulin resistance, and dyslipidemia ${ }^{6}$. Additionally, GDM is associated with adverse short- and long-term effects on both the mother and offspring ${ }^{7,8}$, and increased risk for DM2, MetS and CVD ${ }^{9}$.

In milder forms of GDM, which do not fully meet diagnostic criteria, hyperglycemia and adverse effects to the mother and offspring are also present ${ }^{10}$. In the Perinatal Diabetes Research Centre (PDRC), Botucatu Medical School-UNESP (Sao Paulo State University), Brazil, women with a glycemic profile indicative of hyperglycemia and a normal response to glucose tolerance testing have been identified as having Mild Gestational Hyperglycemia (MGH) and offered the same treatment given to those with GDM for over two decades ${ }^{11,12}$. Today, women with MGH account for $17.3 \%$ of our cases ${ }^{13}$.

Current diagnostic guidelines distinguish diabetes mellitus during pregnancy that is diagnosed before 20 weeks of pregnancy from GDM, which is identified during the second and third trimesters. Most frequently, universal screening is performed by initially measuring FG during the initial visit for prenatal care (before 20 weeks of pregnancy). When neither diabetes in pregnancy ( $F G \geq 126 \mathrm{mg} / \mathrm{dL}$ ) nor GDM (FG $\geq 92$ and $<126 \mathrm{mg} /$ $\mathrm{dL}$ ) is detected, a $75 \mathrm{~g}$-OGTT is offered at 24-28 weeks ${ }^{5,7,14-16}$. However, the cost-effectiveness of this strategy, as well as its effects on short- or long-term maternal and offspring outcomes remain unknown and evidence supporting its use is still insufficient ${ }^{17}$.

\footnotetext{
${ }^{1}$ Graduate Program in Obstetrics, Gynecology and Mastology, Botucatu Medical School, São Paulo State University/Unesp, São Paulo, Brazil. ${ }^{2}$ Department of Gynecology and Obstetrics, Botucatu Medical School, São Paulo State University/Unesp, Botucatu, SP, Brazil. ${ }^{3}$ Department of Biostatistics, Botucatu Institute of Biosciences, São Paulo State University/Unesp, São Paulo, Brazil. ${ }^{4}$ Department of Nursing, Botucatu Medical School, São Paulo State University/Unesp, São Paulo, Brazil. ${ }^{\circledR}$ email: iracema.calderon@gmail.com
} 
Recognized risk factors for GDM include advanced maternal age, family history of diabetes, history of GDM, history of macrosomia, non-Caucasian race or ethinicity, excessive weight gain or obesity during pregnancy, and smoking (actively or passively). However, as the prevalence of such risk factors among women with GDM is low (at most $50 \%)^{18,19}$ and their predictive accuracy is poor, this may lead to unnecessary testing ${ }^{17,20}$.

The association of MetS with maternal hyperglycemia has been documented since the past decade ${ }^{21}$, and MetS has been shown to be more frequent in women with $\mathrm{GDM}^{4,21}$. Studies of BMI, waist circumference (WC), and lipid profile components as independent predictors of GDM have yielded conflicting results ${ }^{22-25}$. However, to the best of our knowledge, the relationship between the MetS markers recommended by different sets of guidelines $^{2-4}$ and risk of MGH or GDM remains uninvestigated. Thus, the objective of this study was to assess the role of the MetS diagnostic markers proposed in three different sets of guidelines-International Diabetes Federation (IDF) ${ }^{2}$, National Cholesterol Education Program's Adult Treatment Panel III (NCEP-ATP III) ${ }^{3}$, and Bartha et al. $^{4}$, in the prediction of hyperglycemia (MGH or GDM) in pregnancy.

\section{Methods}

Study setting and design. This cross-sectional cohort study, undertaken from March 2014 to December 2016, included women with a singleton pregnancy who underwent a 75 g-Oral Glucose Tolerance Test (75 g-OGTT) and Glucose Profile (GP) testing between 24 and 28 weeks of pregnancy. The Mets components were evaluated in the inclusion of the study and previously to diagnostic tests. Women with a previous diagnosis of type 1 or type $2 \mathrm{DM}$, as well as those diagnosed with overt diabetes or GDM before 20 weeks of pregnancy were excluded ${ }^{5}$.

The study was conducted in the Botucatu Public Health Network (the primary care) and in the PDCR-Botucatu Medical School/UNESP, Brazil, our referral center (tertiary care). The study protocol was approved by the Human Subject Research Ethics Committee of Botucatu Medical School/Unesp (\# 3900-2011; Of. No. 244/11). All methods were performed in accordance with the principles of the Brazilian National Heath Council (Resolution CNS 466/12) in compliance with local/institutional guidelines and regulations in all stages of this study.

Sample size. The sample size was based on the prevalence of maternal hyperglycemia between 15 and $20 \%{ }^{13,17}$, the risk of 4.21 for hyperglycemia when pre-BMI $\geq 25 \mathrm{~kg} / \mathrm{m}^{222}$, a type 2 error of $20 \%$, and a $95 \%$ confidence level. According to the assumed prevalence, the minimum sample size resulted in 258 and 194, respectively. A total of 506 pregnant women were included, 283 with gestational age $<24$ and 223 with gestational age $\geq 24$ weeks.

Data collection. At enrollment, all participants were asked to answer a specific structured questionnaire for the collection of epidemiological and clinical data. These included information on prepregnancy weight, used for the calculus of the prepregnancy BMI, weight gain, and family and personal obstetric risk factors for GDM ${ }^{5,18,26}$. Incomplete or missing information was recovered from the participant's prenatal care chart. Also at enrollment, were collected data on blood pressure, height and current weight, to calculate the gestational BMI, and waist circumference $^{27}$, besides blood collection for the analysis of FG, glycated hemoglobin (HbA1c), basal insulin and complete lipid profile (LDL and HDL-cholesterol, total cholesterol and TG).

Variables. The maternal characteristics assessed included: self-reported race (white and non-white), age in complete years (categorized as $<19$ years, 19-35 years, and $>35$ years); number of pregnancies including current (categorized as 1 and $\geq 2$ pregnancies), physical activity (No, Yes, $<150 \mathrm{~min} / \mathrm{week}$, and $\geq 150 \mathrm{~min} /$ week $^{28}$ ), smoking status (yes); presence of risk factors for $\mathrm{DM}^{18,26}$, and gestacional age at enrollment $(<24$ weeks, and $\geq 24$ weeks).

The risk factors were defined by MetS diagnostic markers, recommended by IDF, NCEP-ATP III, and Bartha et al. guidelines ${ }^{2-4}$, presented follow:

\begin{tabular}{|l|l|l|l|}
\hline MetS componentes & IDF $^{3}$ & ${\text { NCEP-ATP } \text { III }^{2}}^{2}$ & Bartha et al. $^{4}$ \\
\hline $\begin{array}{l}\text { Central obesity: waist circumference } \\
(\mathrm{WC} ; \mathrm{cm}) \\
\left(\mathrm{Kg} / \mathrm{m}^{2}\right)\end{array}$ & $\begin{array}{l}\text { Central obesity: WC } \geq 80 \text { OR } \\
\text { pregest BMI } \geq 30\end{array}$ & $\begin{array}{l}\text { Abdominal obesity, given as WC }>2 \\
\text { S.D. for gestational age in the first half } \\
\text { of pregnancy OR } \\
\text { pregest BMI }>30\end{array}$ \\
\hline Triglycerides $(\mathrm{mg} / \mathrm{dL})$ & $\geq 150$ & $\geq 150$ & $\geq 2$ S.D. for gestational age \\
\hline HDL-cholesterol $(\mathrm{mg} / \mathrm{dL})$ & $<50$ & $<50$ & $<2$ S.D. for gestational age \\
\hline Blood pressure $(\mathrm{mmHg})$ & $\geq 130 / \geq 85$ & $\geq 130 / \geq 85$ & $\geq 130 / \geq 85$ \\
\hline Fasting glicose $(\mathrm{mg} / \mathrm{dL})$ & $\geq 100$ OR T2DM & $\geq 110$ & $\geq 105$ \\
\hline MetS criteria & $\begin{array}{l}\text { Central obesity plus any two } \\
\text { of the four factors }\end{array}$ & Any three or more factors & Any three of the five factors \\
\hline
\end{tabular}

GDM and MGH diagnoses. All pregnant women included in the study underwent 75-g oral glucose tolerance test (75 g-OGTT) and glucose profile (GP) tests between 24 and 28 weeks of pregnancy.

GDM was diagnosed if there was one abnormal value $(92,180$ and $153 \mathrm{mg} / \mathrm{dL}$ for fasting, one-hour and twohour postglucose load, respectively), after a $75 \mathrm{~g}$-OGTT $\mathrm{O}^{5,7,14-16}$.

For MGH diagnosis, a GP and a 75 g-OGTT were performed during a 1-day hospital stay with the woman on a $2840 \mathrm{kcal}$-diet fractionated in five meals. Plasma glucose was measured every two hours, from 8 AM to 6 
PM. The thresholds used were $90 \mathrm{mg} / \mathrm{dL}$ for fasting $(8 \mathrm{~h})$ and $130 \mathrm{mg} / \mathrm{dL}$ for any postprandial level. MGH was confirmed when response to 75 g-OGTT was normal and one GP measure was equal or greater than threshold values $^{11,12}$.

Follow-up. Non-diabetic women were followed up at their original primary care center. Women with MGH or GDM were followed up at the PDCR-Botucatu Medical School/UNESP, a tertiary center. In both MGH and GDM cases, maternal hyperglycemia control was performed according to the protocol established in our center as recommended by $\mathrm{ADA}^{5,14}$.

Statistical analyses. Statistical analyses were performed using Statistical Analysis System-9.3.

The results expressed in mean $(\mathrm{m})$ and standard deviation $(\mathrm{sd})$ with symmetric distribution were compared by one-way ANOVA followed by the Tukey test (75 g-OGTT and GP tests, and anthropometric measures); the Gamma test followed by the Wald test (asymmetric distribution) were used to compare means values relative to glucose and lipid profiles. Likewise, Chi-square or Exact Fisher tests (if applicable) were used to test association with MetS criteria according to the guidelines evaluated ${ }^{2-4}$. Two by two proportions were compared using a comparison proportion test based on the normal distribution (similar to chi-square test) by two groups (ND, $\mathrm{MGH}$, and GDM).

The logistic regression model (using backward stepwise) was fitted to identify the independent risk factors for maternal hyperglycemia. It was conducted by two different approaches-one considering all 506 pregnant women included, regardless of the gestational age at enrollment, and another based on metabolic phases of pregnancy, that is $<24$ and $\geq 24$ weeks in the study inclusion. Here, MGH and GDM were assessed as a unique condition-maternal hyperglycemia as the response variable in function of the MetS diagnostic markers ${ }^{2-4}$. The odds ratio (OR) and 95\% confidence intervals (95\% CI) were calculated for each MetS diagnostic markers and adjusted for all other variables within the respective guideline. The initial model included all variables/MetS markers, and the variables were excluded one by one until reaching the final model, defined by the impossibility to exclude any other variable without significant loss in adjustment. The backward elimination criterion was $5 \%$.

Ethical considerations. The study protocol was approved by the Human Subject Research Ethics Committee of Botucatu Medical School/Unesp (\# 3900-2011; Of. No. 244/11). All subjects signed an informed consent form before inclusion in the present study.

Consent for publication. All authors approved the current version and agreed to submit for publication.

\section{Results}

According to 75 g-OGTT response, study participants were assigned to three groups: Non-diabetic (ND, normal 75 g-OGTT and GP); MGH (normal 75 g-OGTT + abnormal GP); and GDM (abnormal 75 g-OGTT + abnormal GP).

The study flowchart (Fig. 1) shows the number of pregnant women included $(\mathrm{N}=517)$, excluded $(\mathrm{N}=3)$, and withdrawn from the study $(\mathrm{N}=8)$, as well as the number of participants in each group- $\mathrm{ND}(\mathrm{N}=430), \mathrm{MGH}$ $(\mathrm{N}=30)$ and GDM $(\mathrm{N}=46)$. Of the 506 women assessed, $283(55.9 \%)$ were included before 24 weeks and 223 $(44.1 \%)$ at $24-30$ weeks of pregnancy.

The characteristics of the 506 study participants are shown in Table 1. A personal and obstetric history of hypertension (6.5\%) and macrossomia (5.1\%), and a family history of GDM (58.1\%) and hypertension (63.2\%) were the most common.

Table 2 shows that the glucose levels in response to diagnostic tests were different among groups, with higher values in the GDM group. Maternal height and the levels of total cholesterol and HDL-c were similar in all groups. The remaining anthropometric and metabolic variables were lower in ND than in the other groups.

MetS frequency, as evaluated using NCEP-ATP III $^{2}$ criteria, was $7.0 \%$ in ND, $16.7 \%$ in $\mathrm{MGH}$, and $21.7 \%$ in $\operatorname{GDM}(p=0.0011)$.

Regarding the MetS diagnostic markers defined by IDF $^{3}$, the proportion of women with HDL-cholesterol $<50 \mathrm{mg} / \mathrm{dL}$ and $\mathrm{WC} \geq 80 \mathrm{~cm}$ did not differ among groups. The proportion of women with $\mathrm{TG} \geq 150 \mathrm{mg} / \mathrm{dL}$, $\mathrm{BP} \geq 130 / 85 \mathrm{mmHg}, \mathrm{FG} \geq 100 \mathrm{mg} / \mathrm{dL}$ and pregestational $\mathrm{BMI} \geq 30 \mathrm{~kg} / \mathrm{m}^{2}$ was statiscally different among groups with higher values in GDM.

According to NCEP-ATP III $^{2}$ MetS protocol, only the frequency of HDL-cholesterol $<50 \mathrm{mg} / \mathrm{dL}$ did not differ among groups, while the proportion of women with TG $\geq 150 \mathrm{mg} / \mathrm{dL}, \mathrm{BP} \geq 130 / 85 \mathrm{mmHg}, \mathrm{FG} \geq 110 \mathrm{mg} / \mathrm{dL}$ and WC $>88 \mathrm{~cm}$ was always higher in GDM. Similar results were obtained with the markers recommended by Bartha et $a l .{ }^{4}$, adapted for pregnancy (Table 3 ).

Considering all 506 pregnant women, the logistic regression analysis revealed that $\mathrm{TG} \geq 150 \mathrm{mg} / \mathrm{dL}$, $\mathrm{BP} \geq 130 / 85 \mathrm{mmHg}, \mathrm{FG} \geq 100 \mathrm{mg} / \mathrm{dL}$ and $\mathrm{WC}>88 \mathrm{~cm}$ are independent risk factors for $\mathrm{MGH}$ and GDM, whereas $\mathrm{HDL}-\mathrm{c}<50 \mathrm{mg} / \mathrm{dL}$ and pregestational $\mathrm{BMI} \geq 30 \mathrm{~kg} / \mathrm{m}^{2}$ are not associated with MGH or GDM risk. In contrast, gestational $\mathrm{BMI} \geq 30 \mathrm{~kg} / \mathrm{m}^{2}$, was an independent risk factor for $\mathrm{MGH}$ and GDM (OR $\left.=2.796 ; 95 \% \mathrm{CI} 1.213-6.446\right)$ (Table 4).

According to the gestational age at enrollment, the logistic regression analysis indicated only WC $>88 \mathrm{~cm}$ $(\mathrm{OR}=2.720 ; 95 \% \mathrm{CI} 1.113-6.647)$ as an independent risk factor for $\mathrm{MGH}$ and GDM before 24 weeks of pregnancy. At $\geq 24$ weeks, TG $\geq 150 \mathrm{mg} / \mathrm{dL}, \mathrm{BP} \geq 130 / 85 \mathrm{mmHg}$ and $\mathrm{FG} \geq 105 \mathrm{mg} / \mathrm{dL}(\mathrm{OR}=20.889 ; 95 \% \mathrm{CI}$ $1.580-276.104)$ or $\geq 100 \mathrm{mg} / \mathrm{dL}(\mathrm{OR}=19.845$; 95\% CI 1.845-213.493) were identified as independent risk factors for hyperglycemia during pregnancy. In this gestational age, no woman showed WC $<88$ or $80 \mathrm{~cm}$ (Table 4). 


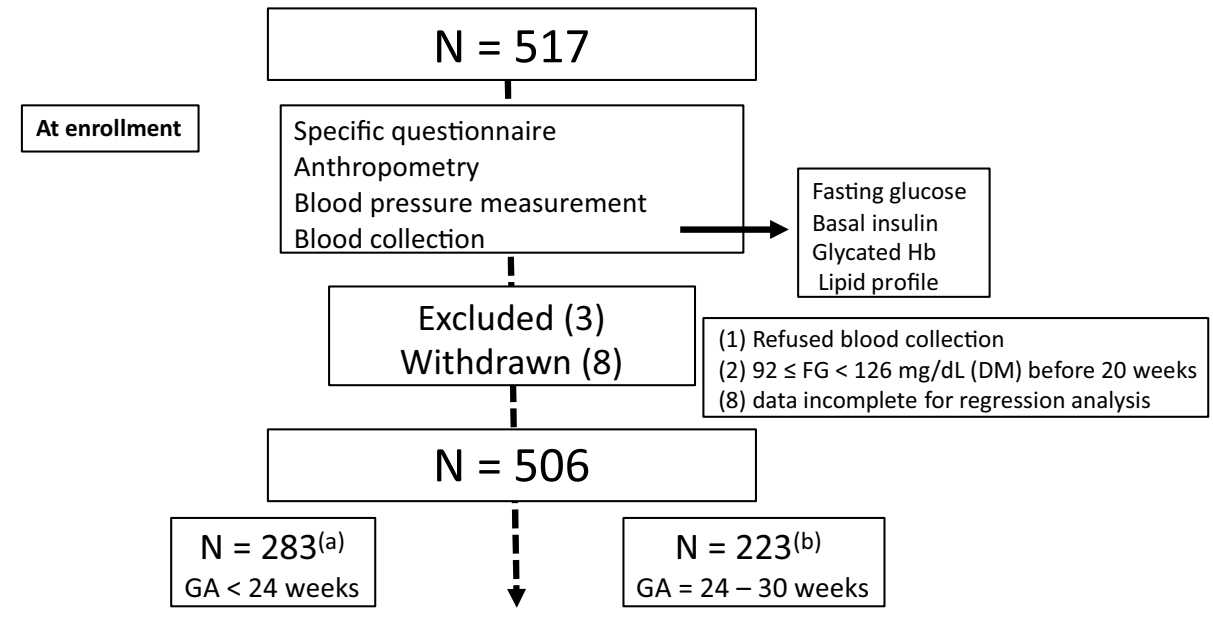

At diagnosis

$$
\begin{gathered}
\text { 75g-OGTT and GP } \\
\text { GA }=24-30 \text { weeks }
\end{gathered}
$$

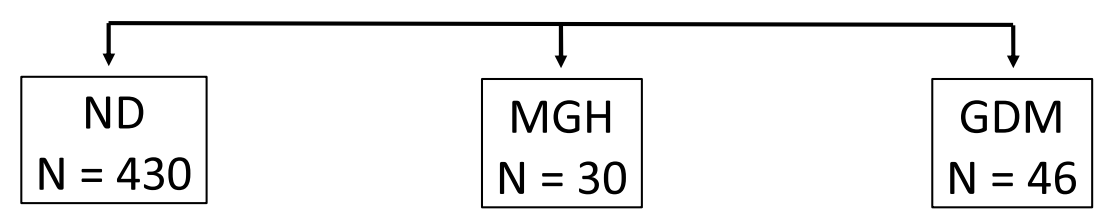

(a) 283 pregnant women with gestational age $<24$ weeks at enrollment, and 75g-OGTT and GP at 24-28 weeks

(b) 283 pregnant women with gestational age $\geq 24$ weeks at enrollment, and 75g-OGTT and GP at 24-30 weeks

Figure 1. Study flowchart.

\section{Discussion}

This study evaluated the role of MetS diagnostic markers recommended by different sets of guidelines ${ }^{2-4}$ in the prediction of $\mathrm{MGH}$ and GDM risk. In the comparison among groups, the proportion of women with $\mathrm{TG} \geq 150 \mathrm{mg} / \mathrm{dL}, \mathrm{BP} \geq 130 / 85 \mathrm{mmHg}, \mathrm{FG} \geq 100 \mathrm{mg} / \mathrm{dL}, \mathrm{WC}>88 \mathrm{~cm}$, and pregestational $\mathrm{BMI} \geq 30 \mathrm{~kg} / \mathrm{m}^{2}$ were larger in GDM than in ND group. In the MGH group, these proportions were statistically comparable to those seen in ND and GDM groups. The thresholds HDL-c $>30.5^{4}$ or $50 \mathrm{mg} / \mathrm{dL}^{2,3}$ and CC $\geq 80 \mathrm{~cm}^{3}$ did not differentiate the proportion of pregnant women with hyperglycemia from those without. These findings reinforce the proportional relation between MetS and glucose status, as previously reported by our team ${ }^{21,29}$.

Considering all 506 pregnant women, the logistic regression analysis indicate that $\mathrm{TG} \geq 150 \mathrm{mg} / \mathrm{dL}^{2,3}$, $\mathrm{BP} \geq 130 / 85 \mathrm{mmHg} \mathrm{m}^{2,3}, \mathrm{FG} \geq 100 \mathrm{mg} / \mathrm{dL}^{2}$ and $\mathrm{WC}>88 \mathrm{~cm}^{2}$ were identified as independent predictors of $\mathrm{MGH}$ or GDM (Table 4). Therefore, according to the physiopathology that points the insulin resistance as the common base to GDM and MetS $\mathrm{S}^{3}$, these values seem adequate for the diagnosis of MetS during pregnancy. On the other hand, $\mathrm{HDL}-\mathrm{c}<50^{2,3}$ or $<30.6 \mathrm{mg} / \mathrm{dL}^{4}$, pre-BMI $\geq 30 \mathrm{~kg} / \mathrm{m}^{23,4}$ and $\mathrm{WC} \geq 80 \mathrm{~cm}^{3}$ or $>126.1 \mathrm{~cm}^{4}$ showed no predictive value to maternal hyperglycemia. However, news values of HDL-c and pregestational BMI should be proposed to MetS criteria in pregnancy.

Before 24 weeks, only WC $>88 \mathrm{~cm}$ and TG $\geq 300 \mathrm{mg} / \mathrm{dL}$ were independently predictive of risk for MGH or GDM. At 24-30 weeks, TG $\geq 150 \mathrm{mg} / \mathrm{dL}, \mathrm{BP} \geq 130 / 85 \mathrm{mmHg}$ and $\mathrm{FG} \geq 100 \mathrm{mg} / \mathrm{dL}$ were identified as independent predictors of MGH or GDM risk. On the other hand, HDL-c $<50 \mathrm{mg} / \mathrm{dL}$ and pregestational BMI $\geq 30 \mathrm{~kg} / \mathrm{m}^{2}$ showed no predictive value at any gestational age.

Some of the markers evaluated in this study have been previously investigated, but individually and independently from MetS diagnostic guidelines ${ }^{2-4}$. Nonetheless, according to these previous studies, pregestational $\mathrm{BMI} \geq 25 \mathrm{~kg} / \mathrm{m}^{2}$ and $\mathrm{WC} \geq 88 \mathrm{~cm}$ are predictive of GDM risk ${ }^{22}$; MetS occurrence is directly associated with the level of glucose intolerance ${ }^{21-29}$; obesity (pregestational BMI $\geq 30 \mathrm{Kg} / \mathrm{m}^{2}$ ) is associated with MGH or GDM risk, and gestational $\mathrm{HbAlc} \geq 6.5 \%{ }^{23}, \mathrm{TG} \geq 137$ and $182 \mathrm{mg} / \mathrm{dL}$ increase the risk of $\mathrm{GDM}^{30}$.

Our findings are consistent with those reported in the literature, but our data regarding FG, BMI and HDL-c are worth of note. The FG values $\geq 100,105$ and $110 \mathrm{mg} / \mathrm{dL}$ established in the guidelines for MetS diagnosis ${ }^{2-4}$ are beyond the limit of $92 \mathrm{mg} / \mathrm{dL}$ recommended for the diagnosis of $\mathrm{GDM}^{5,7,14-16}$. Thus, these results have no clinical application and indicate that FG values should be recalculated and adapted for the diagnosis of MetS during gestation.

In our study, pregestational $\mathrm{BMI} \geq 30 \mathrm{~kg} / \mathrm{m}^{2}$ was not found to be independently predictive of MGH or GDM risk. This was an unexpected finding as it contradicts previous studies ${ }^{17,20,22,23}$. Obesity has been progressively increasing worldwide and, as a result, a larger number of pregnant women has elevated pregestational $\mathrm{BMI}^{3,31}$. In our study population, $1 / 4$ of ND participants had pregestational $\mathrm{BMI} \geq 30 \mathrm{~kg} / \mathrm{m}^{2}$. Additionally, mean BMI 


\begin{tabular}{|c|c|c|}
\hline & \multicolumn{2}{|c|}{$\begin{array}{l}\mathrm{N}=506 \text { pregnant } \\
\text { women }\end{array}$} \\
\hline & $\mathbf{N}$ & $\%$ \\
\hline \multicolumn{3}{|l|}{ Self-reported race } \\
\hline White & 453 & 89.5 \\
\hline Non-white & 53 & 10.5 \\
\hline \multicolumn{3}{|l|}{ Age (complete years) } \\
\hline$<19$ & 72 & 14.2 \\
\hline $19-35$ & 375 & 74.1 \\
\hline$>35$ & 59 & 11.7 \\
\hline \multicolumn{3}{|l|}{ Number of pregnancies } \\
\hline 1 & 172 & 33.60 \\
\hline$\geq 2$ & 334 & 66.40 \\
\hline \multicolumn{3}{|l|}{ Physical activity } \\
\hline No & 358 & 70.8 \\
\hline Yes & 148 & 29.2 \\
\hline$\geq 150 \mathrm{~min} /$ week & 51 & 34.5 \\
\hline$<150 \mathrm{~min} /$ week & 97 & 65.5 \\
\hline Smoking & 125 & 24.7 \\
\hline \multicolumn{3}{|l|}{ Personal and obstetric history } \\
\hline Gestational Diabetes Mellitus & 3 & 0.6 \\
\hline Blood pressure & 33 & 6.5 \\
\hline Polycystic ovary syndrome & 4 & 0.8 \\
\hline Macrossomia & 26 & 5.1 \\
\hline Fetal death & 14 & 2.8 \\
\hline Fetal malformation & 10 & 1.9 \\
\hline \multicolumn{3}{|l|}{ Family history of } \\
\hline Diabetes mellitus & 294 & 58.1 \\
\hline Obesity & 139 & 27.5 \\
\hline Hypertension & 320 & 63.2 \\
\hline Cardiovascular disease & 182 & 35.9 \\
\hline Hypercholesterolemia & 123 & 24.4 \\
\hline \multicolumn{3}{|c|}{ Gestational age(GA) at enrollment } \\
\hline$<24$ weeks & 283 & 55.9 \\
\hline$\geq 24$ weeks & 223 & 44.1 \\
\hline $\mathrm{GA} \leq 12$ weeks & 154 & 30.4 \\
\hline $\mathrm{GA} \geq 13$ and $<19$ weeks & 81 & 16.0 \\
\hline $\mathrm{GA} \geq 19$ and $<24$ weeks & 48 & 9.5 \\
\hline $\mathrm{GA} \geq 24-30$ weeks & 223 & 44.1 \\
\hline GA weeks, mean (sd) & $18.9(7.7)$ & \\
\hline GA weeks, median (min; $\max$ ) & $20(5 ; 30)$ & \\
\hline
\end{tabular}

Table 1. Study participants' characteristics.

indicated overweight $\left(\geq 25 \mathrm{~kg} / \mathrm{m}^{2}\right)$ in ND and obesity $\left(\geq 30 \mathrm{~kg} / \mathrm{m}^{2}\right)$ in MGH and GDM groups. This might have influenced this marker's ability to predict MGH and GDM and points to the necessity of investigating new threshold limits to prepregnancy BMI.

Among our study participants, HDL-c $<50 \mathrm{mg} / \mathrm{dL}^{2-4}$ was not predictive of MGH or GDM. In general, total cholesterol, TG, LDL-c and VLDL-c increase in the second trimester, and are even more greatly increased in the third trimester, whereas HDL-c levels remain unchanged in the second trimester and are decreased in the third trimester. In women with GDM, reduction in lipid measures is even more accentuated ${ }^{24,25,32}$. A recent metanalysis corroborates these results and highlights the progressive increase in TG and significant reduction in HDL-c that occur in the second and third trimesters of pregnancy in women with $\mathrm{GDM}^{33}$.

In this study, mean HDL-c levels were higher than the threshold limit of 30.5 and $50 \mathrm{mg} / \mathrm{dL}$ proposed with no association with maternal glycemic status. The dynamics of lipid profile during pregnancy and the HDL-c levels observed in our population might explain the inability to predict MGH or GDM, and underscore the need for investigating new HDL-c values to be used in the diagnosis of MetS during pregnancy.

Pregestational BMI and WC have been previously identified as predictors of maternal hyperglycemia risk in Brazil ${ }^{22,23}$ and in other countries ${ }^{17,20,34-38}$. However, the establishment of $\mathrm{TG} \geq 150 \mathrm{mg} / \mathrm{dL}$ as an independent predictor of risk of MGH and GDM from 24 weeks of pregnancy onward, seem to be contributions unique to 


\begin{tabular}{|c|c|c|c|c|}
\hline & \multicolumn{4}{|c|}{ N Total = 506 pregnant women } \\
\hline & $\begin{array}{l}\mathrm{ND} \\
\mathrm{N}=430(\text { mean } \pm s d)\end{array}$ & $\begin{array}{l}\text { MGH } \\
\mathbf{N}=\mathbf{3 0}(\text { mean } \pm s d)\end{array}$ & $\begin{array}{l}\text { GDM } \\
N=46(\text { mean } \pm s d)\end{array}$ & $p$-value \\
\hline \multicolumn{5}{|l|}{75 g-OGTT $^{*}$} \\
\hline fasting $(\mathrm{mg} / \mathrm{dL})$ & $73.0 \pm 7.7 \mathrm{a}$ & $79.2 \pm 8.2 \mathrm{~b}$ & $95.9 \pm 16.8 \mathrm{c}$ & $<0.0001$ \\
\hline $1 \mathrm{~h}(\mathrm{mg} / \mathrm{dL})$ & $113.1 \pm 24.2 \mathrm{a}$ & $132.1 \pm 24.1 \mathrm{~b}$ & $169.2 \pm 37.7 \mathrm{c}$ & $<0.0001$ \\
\hline $2 \mathrm{~h}(\mathrm{mg} / \mathrm{dL})$ & $96.2 \pm 20.5 \mathrm{a}$ & $110.1 \pm 21.2 \mathrm{~b}$ & $141.2 \pm 42.7 \mathrm{c}$ & $<0.0001$ \\
\hline \multicolumn{5}{|l|}{$\mathbf{G P}^{*}$} \\
\hline fasting $(\mathrm{mg} / \mathrm{dL})$ & $74.4 \pm 7.1 \mathrm{a}$ & $87.7 \pm 12.8 \mathrm{ab}$ & $88.2 \pm 13.4 \mathrm{~b}$ & $<0.0001$ \\
\hline $2 \mathrm{~h}$ after breakfast $(\mathrm{mg} / \mathrm{dL})$ & $85.3 \pm 16.7 \mathrm{a}$ & $101.2 \pm 26.5 b$ & $113.0 \pm 27.7 \mathrm{c}$ & $<0.0001$ \\
\hline Pre-lunch (mg/dL) & $65.9 \pm 11.3 \mathrm{a}$ & $72.2 \pm 13.6 \mathrm{~b}$ & $73.8 \pm 16.3 \mathrm{~b}$ & $<0.0001$ \\
\hline $2 \mathrm{~h}$ post-lunch $(\mathrm{mg} / \mathrm{dL})$ & $92.5 \pm 17.2 \mathrm{a}$ & $121.2 \pm 26.7 \mathrm{~b}$ & $109.3 \pm 23.9 \mathrm{c}$ & $<0.0001$ \\
\hline \multicolumn{5}{|l|}{ Anthropometric measures ${ }^{*}$} \\
\hline Age (years) & $26.4 \pm 6.49 \mathrm{a}$ & $28.8 \pm 6.8 \mathrm{ab}$ & $30.6 \pm 5.7 \mathrm{~b}$ & $<0.0001$ \\
\hline Height $(\mathrm{cm})$ & $1.6 \pm 0.06$ & $1.6 \pm 0.1$ & $1.6 \pm 0.1$ & 0.9982 \\
\hline Pregestational weight (kg) & $68.65 \pm 17.84 a$ & $78.2 \pm 22.5 b$ & $81.0 \pm 23.7 \mathrm{~b}$ & $<0.0001$ \\
\hline Pregestational BMI $\left(\mathrm{kg} / \mathrm{m}^{2}\right)$ & $26.65 \pm 6.66 \mathrm{a}$ & $30.2 \pm 7.3 \mathrm{~b}$ & $31.2 \pm 7.7 \mathrm{~b}$ & $<0.0001$ \\
\hline Gestational weight $(\mathrm{kg})$ & $72.09 \pm 17.58 \mathrm{a}$ & $81.2 \pm 23.7 \mathrm{~b}$ & $85.7 \pm 22.7 \mathrm{~b}$ & $<0.0001$ \\
\hline Gestational BMI $\left(\mathrm{kg} / \mathrm{m}^{2}\right)$ & $27.99 \pm 6.49 a$ & $31.36 \pm 7.6 \mathrm{~b}$ & $33.1 \pm 7.2 \mathrm{~b}$ & $<0.0001$ \\
\hline Waist circumference $(\mathrm{cm})$ & $95.04 \pm 13.6 \mathrm{a}$ & $101.6 \pm 17.4 \mathrm{~b}$ & $108.2 \pm 15.5 b$ & $<0.0001$ \\
\hline $\mathrm{SBP}(\mathrm{mm} / \mathrm{Hg})$ & $109.87 \pm 12.75 \mathrm{a}$ & $114.0 \pm 14.3 \mathrm{ab}$ & $116.1 \pm 13.3 \mathrm{~b}$ & 0.0032 \\
\hline $\mathrm{DBP}(\mathrm{mm} / \mathrm{Hg})$ & $67.39 \pm 10.15 a$ & $71.3 \pm 10.8 \mathrm{ab}$ & $72.38 \pm 10.9 b$ & 0.0018 \\
\hline \multicolumn{5}{|l|}{ Glucose and lipid variables } \\
\hline Glycated $\mathrm{Hb}(\mathrm{mg} / \mathrm{dL})^{\#}$ & $4.95 \pm 0.44 \mathrm{a}$ & $5.2 \pm 10.6 \mathrm{~b}$ & $5.3 \pm 0.4 \mathrm{~b}$ & $<0.0001$ \\
\hline Fasting glucose $(\mathrm{mg} / \mathrm{dL})^{*}$ & $71.38 \pm 8.56 \mathrm{a}$ & $77.1 \pm 12.4 \mathrm{~b}$ & $84.0 \pm 13.7 \mathrm{c}$ & $<0.0001$ \\
\hline Basal Insulina $(\mathrm{mg} / \mathrm{dL})^{\#}$ & $8.5 \pm 11.2 \mathrm{a}$ & $16.5 \pm 22.1 b$ & $12.7 \pm 10.1 b$ & $<0.0001$ \\
\hline Total cholesterol $(\mathrm{mg} / \mathrm{dL})^{*}$ & $203.24 \pm 45.56$ & $197.7 \pm 40.4$ & $212.1 \pm 44.5$ & 0.3421 \\
\hline HDL-cholesterol $(\mathrm{mg} / \mathrm{dL})^{*}$ & $66.43 \pm 18.35$ & $63.4 \pm 15.7$ & $67.4 \pm 13.6$ & 0.6014 \\
\hline Triglycerides $(\mathrm{mg} / \mathrm{dL})^{\#}$ & $153.52 \pm 66.75 \mathrm{a}$ & $167.0 \pm 82.0 \mathrm{ab}$ & $198.2 \pm 85.7 \mathrm{~b}$ & 0.0003 \\
\hline
\end{tabular}

Table 2. Diagnostic testing results, anthropometric measures, glucose and lipid variables in the study groups ND, MGH and GDM. Values of each specific variable followed by the same letter (a or b or c) are not significantly different $(p \geq 0.05)$. ND non diabetic, $M G H$ mildgestationalhyperglycemia, GDM diabetes mellitus gestacional, $75 \mathrm{~g}$-OGTT $75 \mathrm{~g}$ oral glucose tolerancetestlicose, GP glucose profile, Pre BMI body mass index based on pregestational weight, $S B P$ systolic blood pressure, $D B P$ diastolic blood pressure. ${ }^{\star}$ Anova followed by Tukey test. "Means compared using gamma distribution followed by Wald test.

this study. The literature shows conflicting results. While some studies do consider TG an independent risk predictor, but only in the first half of pregnancy, others have not associated it with GDM risk ${ }^{24,30,39}$. Nonetheless, the physiological events that take place in the second half of pregnancy-insulin resistance due to the action of the placental hormones, maternal catabolism by rising fetal demands, and a greater increase in TG levels during the third trimester ${ }^{33,40}$ seem to support our findings.

Study limitations. Although the sample size was enough, the results of the current study should be limited to its setting and population, and future studies in different centers are necessary before clinical application. In addition, gestational age at enrollment, which indicated the timing of MetS markers assessment, ranged from 5 to 30 weeks (total of 26 weeks). Before 24 weeks, gestational age at enrollment ranged from 5 to 23 weeks (total of 19 weeks), and after 24 weeks it ranged from 24 to 30 weeks (total of 7 weeks). Thus, in order to equalize the time periods, the group gestational age $<24$ weeks should have been split into 5-12, 13-18, and 19-23 weeks. However, as shown in Table 2, this would reduce the number of samples in each gestational age group and weaken statistical power. In contrast, the novelty in testing the SM markers, defined by three different protocols, in the prediction of the GDM represents the strength of the our study.

Clinical implications. Our results showed that some MetS markers were identified as independent risk factors for hyperglycemia in pregnancy. So, both in the first and second half of pregnancy, TG $\geq 150 \mathrm{mg} /$ 


\begin{tabular}{|c|c|c|c|c|}
\hline & \multicolumn{4}{|c|}{ N Total = 506 pregnant women } \\
\hline & $\begin{array}{l}\text { ND } \\
\mathrm{N}=\mathbf{4 3 0}\end{array}$ & $\begin{array}{l}\text { MGH } \\
\mathbf{N}=30\end{array}$ & $\begin{array}{l}\text { GDM } \\
\mathrm{N}=46\end{array}$ & $p$-value \\
\hline \multicolumn{5}{|l|}{ IDF $^{3}$} \\
\hline HDL-cholesterol $<50 \mathrm{mg} / \mathrm{dL}$ & $72(16.8)$ & $4(13.3)$ & $3(6.5)$ & 0.1807 \\
\hline Triglycerides $\geq 150 \mathrm{mg} / \mathrm{dL}$ & $195(45.4) \mathrm{a}$ & $16(53.3) \mathrm{ab}$ & $35(76.1) \mathrm{b}$ & 0.0003 \\
\hline Blood pressure $\geq 130 / \geq 85 \mathrm{mmHg}$ & $6(1.4) \mathrm{a}$ & $2(6.9) \mathrm{ab}$ & $6(13.3) b$ & $<0.0001$ \\
\hline Fasting glucose $\geq 100 \mathrm{mg} / \mathrm{dL}$ & $0(0.0) \mathrm{a}$ & $1(3.3) \mathrm{ab}$ & $5(10.9) \mathrm{b}$ & 0.0002 \\
\hline Waist circumference $\geq 80 \mathrm{~cm}$ & $375(89.1)$ & $28(93.3)$ & $45(100.0)$ & 0.0693 \\
\hline Pregestational $\mathrm{BMI} \geq 30 \mathrm{~kg} / \mathrm{m}^{2}$ & $107(24.9) \mathrm{a}$ & $13(43.3) \mathrm{b}$ & $20(43.5) \mathrm{b}$ & 0.0039 \\
\hline \multicolumn{5}{|l|}{ NCEP-ATP III ${ }^{2}$} \\
\hline HDL-cholesterol $<50 \mathrm{mg} / \mathrm{dL}$ & $72(16.8)$ & $4(13.3)$ & $3(6.5)$ & 0.1807 \\
\hline Triglycerides $\geq 150 \mathrm{mg} / \mathrm{dL}$ & $195(45.4) \mathrm{a}$ & $16(53.3) \mathrm{ab}$ & $35(76.1) \mathrm{b}$ & 0.0003 \\
\hline Blood pressure $\geq 130 / \geq 85 \mathrm{mmHg}$ & $6(1.4) \mathrm{a}$ & $2(6.9) \mathrm{ab}$ & $6(13.3) b$ & $<0.0001$ \\
\hline Fasting glucose $\geq 110 \mathrm{mg} / \mathrm{dL}$ & $0(0.0) \mathrm{a}$ & $1(3.3) \mathrm{ab}$ & $2(4.3) \mathrm{b}$ & $<0.0001$ \\
\hline Waist circumference $>88 \mathrm{~cm}$ & $286(66.5) \mathrm{a}$ & $24(80.0) \mathrm{ab}$ & $44(95.7) \mathrm{b}$ & 0.0001 \\
\hline \multicolumn{5}{|l|}{ Bartha et al. $^{4}$} \\
\hline HDL-cholesterol $<30.50 \mathrm{mg} / \mathrm{dL}$ & $3(0.7)$ & $0(0.0)$ & $0(0.0)$ & 0.7659 \\
\hline Triglycerides $\geq 299.94 \mathrm{mg} / \mathrm{dL}$ & $10(2.3) \mathrm{a}$ & $1(3.33) \mathrm{ab}$ & $6(13.0) b$ & 0.0006 \\
\hline Blood pressure $\geq 130 / \geq 85 \mathrm{mmHg}$ & $6(1.4) \mathrm{a}$ & $2(6.9) \mathrm{ab}$ & $6(13.3) b$ & $<0.0001$ \\
\hline Fasting glucose $\geq 105 \mathrm{mg} / \mathrm{dL}$ & $0(0.0) \mathrm{a}$ & $1(3.3) \mathrm{ab}$ & $3(6.5) b$ & $<0.0001$ \\
\hline Waist circumference $>126.1 \mathrm{~cm}$ & $5(1.2) \mathrm{a}$ & $1(3.33) \mathrm{ab}$ & $6(13.3) b$ & $<0.0001$ \\
\hline Pregestational $\mathrm{BMI} \geq 30 \mathrm{~kg} / \mathrm{m}^{2}$ & $107(24.8) \mathrm{a}$ & $13(43.3) \mathrm{b}$ & $20(43.5) \mathrm{b}$ & 0.0039 \\
\hline
\end{tabular}

Table 3. Association analysis: MetS diagnostic markers ${ }^{2-4}$ and development of MGH or GDM during pregnancy. Chi-square or Exact Fisher tests (if applicable) to test the association with MetS criteria in each guideline, followed by the comparison proportion test based on the normal distribution (similar to chi-square test) including two groups and two by two proportions. Values of each specific variable followed by the same letter ( $\mathrm{a}$ or $\mathrm{b})$ are not significantly different $(p \geq 0.05)$. ND non diabetic, $M G H$ mild gestational hyperglycemia, GDM diabetes mellitus gestacional, HDL-cholesterol high density lipoprotein, Pre BMI body mass index based on pregestational weight.

$\mathrm{dL}, \mathrm{BP} \geq 130 / 85 \mathrm{mmHg}, \mathrm{FG} \geq 100 \mathrm{mg} / \mathrm{dL}$ and $\mathrm{WC}>88 \mathrm{~cm}$ are independent risk factors for MGH and GDM; $\mathrm{HDL}-\mathrm{c}<50 \mathrm{mg} / \mathrm{dL}$ and pregestational $\mathrm{BMI} \geq 30 \mathrm{~kg} / \mathrm{m}^{2}$ are not associated with $\mathrm{MGH}$ or GDM risk. In contrast, gestational $\mathrm{BMI} \geq 30 \mathrm{~kg} / \mathrm{m}^{2}$, was an independent risk factor for $\mathrm{MGH}$ and GDM.

In the clinical practice, and at any gestational age, $\mathrm{TG} \geq 150 \mathrm{mg} / \mathrm{dL}, \mathrm{BP} \geq 130 / 85 \mathrm{mmHg}, \mathrm{WC}>88 \mathrm{~cm}$, and $\mathrm{BMI} \geq 30 \mathrm{~kg} / \mathrm{m}^{2}$ can be used as screeners associated with the selective diagnostic protocol of MGH or GDM. Ultimately, they would be interpreted as warning signs for hyperglycemia in pregnancy. Considering the cut-off $(F G \geq 92 \mathrm{mg} / \mathrm{dL}$ ) in the current GDM diagnostic protocol (IADPSG, 2010; ADA, 2011), FG $\geq 100 \mathrm{mg} / \mathrm{dL}$ would not useful. The same argument could be done with the results obtained in the first $(<24$ weeks $)$ and the second $(\geq 24$ weeks) half of the pregnancy.

Research implications. Our results were defined after two different approaches, one based on any gestational age at enrollment, and another according to metabolic phases of pregnancy. Although the sample size was enough for both strategies, the gestational age variation among the subjects (Table 1) may have influenced some results. Moreover, these results are limited to a population of pregnant women with characteristics of their own. Therefore, further studies are needed to (1) reevaluate the threshold limits defined by the MetS diagnostic guidelines; (2) assess the uselfulness of these markers in the prediction of MGH or GDM risk using more restricted gestational age ranges; (3) assess the repeatability of these markers in different populations; (4) to determine the actual role of lipid profile in the physiopathology of hyperglycemia in pregnancy.

Finally, some MetS diagnostic markers recommended by different guidelines can independently predict the risk of MGH and GDM. These findings have important clinical implications as they might help to identify women at risk in the selective screening for hyperglycemia in pregnancy. However, other cut-off points were unable to predict this condition and news studies are necessary to adapt them to metabolic changes of pregnancy. 


\begin{tabular}{|c|c|c|c|c|c|c|}
\hline & \multicolumn{2}{|l|}{$N=506$} & \multicolumn{2}{|c|}{$\begin{array}{l}\mathrm{N}=283 \\
\mathrm{GA}<24 \text { weeks }\end{array}$} & \multicolumn{2}{|c|}{$\begin{array}{l}\mathrm{N}=223 \\
\mathrm{GA} \geq 24 \text { weeks }\end{array}$} \\
\hline & OR & $95 \% \mathrm{CI}$ & OR & $95 \% \mathrm{CI}$ & OR & $95 \% \mathrm{CI}$ \\
\hline \multicolumn{7}{|l|}{ IDF $^{3}$} \\
\hline HDL-cholesterol $<50 \mathrm{mg} / \mathrm{dL}$ & 0.619 & $0.265-1.449$ & 1.012 & $0.385-2.659$ & 0.198 & $0.024-1.604$ \\
\hline Triglycerides $\geq 150 \mathrm{mg} / \mathrm{dL}$ & 2.152 & $1.217-3.805$ & 1.030 & $0.453-2.342$ & 5.860 & $1.703-20.166$ \\
\hline Blood pressure $\geq 130 / \geq 85 \mathrm{mmHg}$ & 4.853 & $1.553-15.172$ & 2.217 & $0.394-12.477$ & 8.420 & $1.325-53.510$ \\
\hline Fasting glucose $\geq 100 \mathrm{mg} / \mathrm{dL}$ & 26.951 & $2.628-276.409$ & - & - & 19.845 & $1.845-213.493$ \\
\hline Waist circumference $\geq 80 \mathrm{~cm}$ & 2.245 & $0.502-10.043$ & 1.995 & $0.428-9.298$ & $\mathrm{NA}^{*}$ & $\mathrm{NA}^{*}$ \\
\hline Pregestational $\mathrm{BMI} \geq 30 \mathrm{~kg} / \mathrm{m}^{2}$ & 0.870 & $0.363-2.087$ & 0.897 & $0.198-4.070$ & 0.867 & $0.283-2.652$ \\
\hline \multicolumn{7}{|l|}{ NCEP-ATP III $^{2}$} \\
\hline HDL-cholesterol $<50 \mathrm{mg} / \mathrm{dL}$ & 0.545 & $0.233-1.277$ & 0.962 & $0.369-2.507$ & 0.173 & $0.021-1.405$ \\
\hline Triglycerides $\geq 150 \mathrm{mg} / \mathrm{dL}$ & 2.121 & $1.217-3.699$ & 1.045 & $0.470-2.325$ & 5.586 & $1.624-19.211$ \\
\hline Blood pressure $\geq 130 / \geq 85 \mathrm{mmHg}$ & 7.091 & $2.498-20.126$ & 2.618 & $0.486-14.109$ & 12.601 & $2.287-69-419$ \\
\hline Fasting glucose $\geq 110 \mathrm{mg} / \mathrm{dL}$ & 17.199 & $1.376-214.963$ & - & - & 12.601 & $0.979-162.129$ \\
\hline Waist circumference $>88 \mathrm{~cm}$ & 3.301 & $1.433-7.605$ & 2.720 & $1.113-6.647$ & $\mathrm{NA}^{*}$ & $\mathrm{NA}^{*}$ \\
\hline \multicolumn{7}{|l|}{ Bartha et al. $^{4}$} \\
\hline HDL-cholesterol $<30.50 \mathrm{mg} / \mathrm{dL}$ & - & - & - & - & - & - \\
\hline Triglycerides $\geq 299.94 \mathrm{mg} / \mathrm{dL}$ & 3.978 & $1.313-12.051$ & 9.891 & $1.191-83.167$ & 2.321 & $0.592-9.100$ \\
\hline Blood pressure $\geq 130 / \geq 85 \mathrm{mmHg}$ & 4.540 & $1.446-14.255$ & 1.922 & $0.300-12.337$ & 11.751 & $1.832-75.359$ \\
\hline Fasting glucose $\geq 105 \mathrm{mg} / \mathrm{dL}$ & 27.086 & $2.145-341.967$ & - & - & 20.889 & $1.580-276.104$ \\
\hline Waist circumference $>126.12 \mathrm{~cm}$ & 3.621 & $0.954-1.755$ & 8.039 & $0.615-105.043$ & 2.183 & $0.395-12.053$ \\
\hline Pregestational $\mathrm{BMI} \geq 30 \mathrm{~kg} / \mathrm{m}^{2}$ & 0.652 & $0.268-1.586$ & 0.779 & $0.168-3.618$ & 0.648 & $0.208-2.015$ \\
\hline Gestational $\mathrm{BMI} \geq 30 \mathrm{~kg} / \mathrm{m}^{2}$ & 2.796 & $1.213-6.446$ & 2.946 & $0.677-12.813$ & 2.118 & $0.731-6.132$ \\
\hline
\end{tabular}

Table 4. Logistic regression analysis: OR and $95 \% \mathrm{CI}$ of MetS diagnostic markers ${ }^{2-4}$ for predicting MGH or GDMNA. OR odds ratio, 95\% CI 95\% confidence interval, HDL-cholesterol high density lipoprotein, Pregestational $B M I$ body mass index based on pregestational weight. ${ }^{\star} \mathrm{NA}=$ not assessed; no woman with $\mathrm{WC}<88$ or $80 \mathrm{~cm}$ in this gestational age.

\section{Data availability}

The data sets generated and analyzed in the current study may be made available by the corresponding author if requested.

Received: 12 May 2020; Accepted: 29 October 2020

Published online: 03 December 2020

\section{References}

1. Kassi, E., Pervanidou, P., Kaltsas, G. \& Chrousos, G. Metabolic syndrome: definitions and controversies. BMC Med. 9, 48 (2011).

2. Expert Panel on Detection, Evaluation and Treatment of High Blood Cholesterol in Adults. Executive Summary of the third report of the National Cholesterol Education Program (NCEP) Expert Panel on detection, evaluation, and treatment of high blood cholesterol in adults (Adult Treatment Panel III). JAMA. 18, 126-32 (2001).

3. International Diabetes Federation (IDF). The IDF consensus worldwide definition of the metabolic syndrome [Internet]. Brussels:IDF (2006).

4. Bartha, J. L. et al. Metabolic syndrome in normal and complicated pregnancies. Eur. J. Obstet. Gynecol. Reprod. Biol. 137, 178-184 (2008).

5. American Diabetes Association. Classification and diagnosis of diabetes. Diabetes Care 40, S11-24 (2017).

6. Fasshauer, M., Blüher, M. \& Stumvoll, M. Adipokines in gestational diabetes. Lancet Diabetes Endocrinol. 2, 488-499 (2014).

7. International Association of Diabetes and Pregnancy Study Groups. Recommendations on the diagnosis and classification of hyperglycemia in pregnancy. Diabetes Care 33, 676-682 (2010).

8. O'Sullivan, E.P., Avalos, G., O'Reilly, M., Dennedy, M.C., Gaffney, G., Dunne. F. Atlantic DIP Collaborators. Atlantic DIP: the prevalence and consequences of gestational diabetes in Ireland. Ir. Med. J. 105, 13-5 (2012).

9. Vrachnis, N. et al. Previous gestational diabetes mellitus and markers of cardiovascular risk. Int. J. Endocrinol. https://doi. org/10.1155/2012/458610 (2012).

10. Rice, M.M., Landon, M.B. What we have learned about treating mild gestational diabetes mellitus. Semin. Perinatol. 40, 298-302. https://doi.org/10.1053/j.semperi.2016.03.006(2016).

11. Rudge, M. V., Peraçoli, J. C., Berezowski, A. T., Calderon, I. M. \& Brasil, M. A. The oral glucose tolerance test is a poor predictor of hyperglycemia during pregnancy. Braz. J. Med. Biol. Res. 23, 1079-1089 (1990).

12. Rudge, M. V. C. et al. Hiperglicemia materna diária diagnosticada pelo perfil glicêmico: um problema de saúde pública materno e perinatal. Rev. Bras. Ginecol. Obstet. 27(11), 691-697 (2005).

13. Sirimarco, M.P. et al. Diagnostic protocol for gestational diabetes mellitus (GDM) (IADPSG/ADA, 2011): influence on the occurrence of GDM and mild gestational hyperglycemia (MGH) and on the perinatal outcomes. Diabetol. Metab. Syndr. 9, 1. https:// doi.org/10.1186/s13098-016-02002 (2017).

14. American Diabetes Association. Standards of medical care in diabetes: 2011. Diabetes Care 34, S11-61. https://doi.org/10.2337/ dc11-S011 (2011). 
15. World Health Organization. Diagnostic criteria and classification of hyperglycaemia first detected in pregnancy (WHO, Geneva, 2013).

16. American College of Obstetricians and Gynecologists. Practice Bulletin No. 137: diabetes mellitus gestacional. Obstet. Gynecol. Clin. 122, 406-16. https://doi.org/10.1097/01.AOG.0000433006.09219.f1 (2013).

17. Farrar, D. Hyperglycemia in pregnancy: prevalence, impact, and management challenges. Int. J. Women's Health. 8, 519-527 (2016).

18. Zhang, C., Rawal, S. \& Chong, Y. Risk factors for gestational diabetes: is prevention possible?. Diabetologia 59, 1385-1390. https ://doi.org/10.1007/s00125-016-3979-3 (2016).

19. Bao, W. et al. Parental smoking during pregnancy and the risk of gestational diabetes in the daughter. Int. J. Epidemiol. 45, 160-169. https://doi.org/10.1093/ije/dyv334 (2016).

20. Farrar, D. et al. Risk factor screening to identify women requiring oral glucose tolerance testing to diagnose gestational diabetes: a systematic review and meta-analysis and analysis of two pregnancy cohorts. PLoS ONE 12, e0175288. https://doi.org/10.1371/ journal.pone.0175288 (2017).

21. Negrato, C. A. et al. Mild Gestacional hyperglycemia as a risk factor for metabolic syndrome in pregnancy and adverse perinatal outcomes. Diabetes Metab. Res. Rev. 24, 324-330. https://doi.org/10.1002/dmrr.815 (2008).

22. Bolognani, C. V., Reis, L. B. S. M., Dias, A., Rudge, M. V. C. \& Calderon, I. M. P. Waist circumference in predicting gestational diabetes mellitus. J. Matern. Fetal Neonatal. Med. 27, 9438. https://doi.org/10.3109/14767058.2013.847081 (2014).

23. Vernini, J. et al. Maternal and fetal outcomes in pregnancies complicated by overweight and obesity. Reprod. Health. 13, 100. https ://doi.org/10.1186/s12978-016-0206-0 (2016)

24. Ghodke, B., Pusukuru, R. \& Mehta, V. Association of lipid profile in pregnancy with preeclampsia, gestational diabetes mellitus, and preterm delivery. Cureus. 9, e1420. https://doi.org/10.7759/cureus.1420 (2017).

25. Pusukuru, R. et al. Evaluation of lipid profile in second and third trimester of pregnancy. J. Clin. Diagn. Res. 10, QC12-6. DOI: https://doi.org/10.7860/JCDR/2016/17598.7436 (2016).

26. Sociedade Brasileira de Diabetes. Diretrizes da Sociedade Brasileira de Diabetes (2015-2016). Diabetes mellitus gestacional: diagnóstico, tratamento e acompanhamento pós-gestação. São Paulo: A.C. Farmacêutica. 69-73 (2016).

27. Ministério da Saúde (BR). Orientações para coleta e análise de dados antropométricos em serviços de saúde: norma técnica do sistema de Vigilância Alimentar e Nutricional - SISVAN. Brasília: Ministério da Saúde; Série G. Estatística e Informação em Saúde (2011).

28. ACOG Committee Opinion No. 650: physical activity and exercise during pregnancy and the postpartum period. Obstet Gynecol. 126, e135-e142. https://doi.org/10.1097/AOG.0000000000001214 (2015).

29. Negrato, C. A. et al. Association between different levels of dysglycemia and metabolic syndrome in pregnancy. Diabetol Metab Syndr. 26, 3. https://doi.org/10.1186/1758-5996-1-3 (2009).

30. Kumru, P. et al. Prediction of gestational diabetes mellitus at first trimester in low-risk pregnancies. Taiwan J. Obstet. Gynecol. 55 , 815-820. https://doi.org/10.1016/j.tjog.2016.04.032 (2016).

31. American Diabetes Association. Diagnosis and classification of diabetes mellitus. Diabetes Care 34, S62-S69. https://doi. org/10.2337/dc11-S062 (2011).

32. Jamil, A. A. T. et al. Assessment of lipid profile in sudanese pregnant women. Key. Res. J. Biotechnol. 1, 4-15 (2013).

33. Ryckman, K. K., Spracklen, C. N., Smith, C. J., Robinson, J. G. \& Saftlas, A. F. Maternal lipid levels during pregnancy and gestational diabetes: a systematic review and meta-analysis. BJOG 122, 643-651. https://doi.org/10.1111/1471-0528.13261 (2015).

34. Torloni, M. R. et al. Prepregnancy BMI and the risk of gestational diabetes: a systematic review of the literature with meta-analysis. Obes. Rev. 10, 194-203. https://doi.org/10.1111/j.1467789X.2008.00541.x (2009).

35. Teede, H. J., Harrison, C. L., Teh, W. T., Paul, E. \& Allan, C. A. Gestational diabetes: development of an early risk prediction tool to facilitate opportunities for prevention. Aust. N Z J. Obstet. Gynaecol. 51, 499-504. https://doi.org/10.1111/j.1479-828X.2011.01356 .x (2011).

36. Van Leeuwen, M. et al. Estimating the risk of gestational diabetes mellitus: a clinical prediction model based on patient characteristics and medical history. BJOG 117, 69-75. https://doi.org/10.1111/j.1471-0528.2009.02425.x (2010).

37. Savona-Ventura, C., Vassallo, J., Marre, M. \& Karamanos, B. G. A com- posite risk assessment model to screen for gestational diabetes mellitus among Mediterranean women. Int. J. Gynaecol. Obstet. 120, 240-244. https://doi.org/10.1016/j.ijgo.2012.10.016 (2013).

38. Theriault, S., Forest, J. C., Masse, J. \& Giguere, Y. Validation of early risk-prediction models for gestational diabetes based on clinical characteristics. Diabetes Res. Clin. Pract. 103, 419-425. https://doi.org/10.1016/j.diabres.2013.12.009 (2014).

39. Vitoratos, N. et al. Maternal homocysteine levels and plasma lipids in gestational diabetes: is there any relationship?. J. Obstet. Gynaecol. 22, 366-369 (2002).

40. Herrera, E. \& Ortega-Senovilla, H. Disturbances in lipid metabolism in diabetic pregnancy-are these the cause of the problem?. Best Pract. Res. Clin. Endocrinol. Metab. 24, 515-525. https://doi.org/10.1016/j.beem.2010.05.006 (2010).

\section{Acknowledgements}

The authors are thankful to the Research Support Center (GAP) of Botucatu Medical School, Unesp, for assisting with statistical analyses. To the São Paulo Research Foundation for providing a research Grant [FAPESP Grant 12/51257-9 CNPq-PPSUS]. To National Council for Scientific and Technological Development (CNPq), for the researcher scholarship [PQ-CNPq\#304771/2015-5].

\section{Author contributions}

I.M.C. conceived, designed and coordinated the study. J.M.V., B.F.N., and M.A.A. collected data; J.M.V. wrote and discussed the first manuscript version. J.E.C. was responsible for the statistical analysis. B.F.N., R.A.A.C., C.G.M., S.A.M.L., M.V.R., and I.M.C. contributed to the discussion and reviewed/edited the manuscript. All authors read and approved the final manuscript version.

\section{Competing interests}

The authors declare no competing interests.

\section{Additional information}

Correspondence and requests for materials should be addressed to I.M.C.

Reprints and permissions information is available at www.nature.com/reprints.

Publisher's note Springer Nature remains neutral with regard to jurisdictional claims in published maps and institutional affiliations. 
(c) (i) Open Access This article is licensed under a Creative Commons Attribution 4.0 International cc) License, which permits use, sharing, adaptation, distribution and reproduction in any medium or format, as long as you give appropriate credit to the original author(s) and the source, provide a link to the Creative Commons licence, and indicate if changes were made. The images or other third party material in this article are included in the article's Creative Commons licence, unless indicated otherwise in a credit line to the material. If material is not included in the article's Creative Commons licence and your intended use is not permitted by statutory regulation or exceeds the permitted use, you will need to obtain permission directly from the copyright holder. To view a copy of this licence, visit http://creativecommons.org/licenses/by/4.0/.

(C) The Author(s) 2020 